\title{
Al rescate de la oralidad: el arte de contar en el occidente africano*
}

\author{
Ana Belén Soto \\ Universidad Autónoma de Madrid \\ anabelen.soto@uam.es \\ ORCID: 0000-0001-8164-8420
}

Especialista en literaturas africanas, Vicente E. Montes Nogales pu-

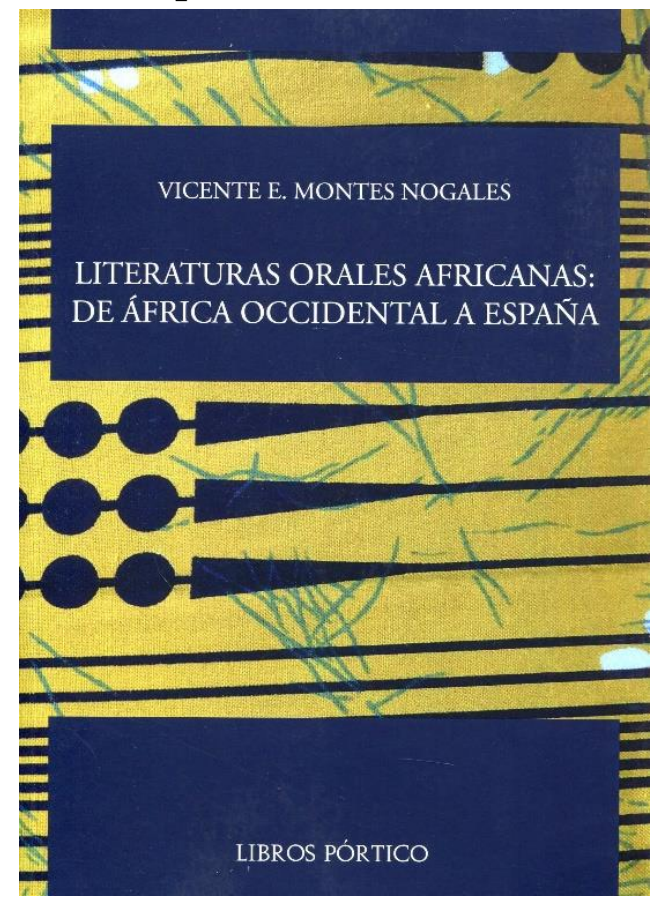
blica en 2020 el resultado de un largo proceso de investigación y de recopilación documental con el objetivo de acercar las literaturas orales del oeste de África a un público hispanohablante. Es así cómo, bajo el título de $L i$ teraturas orales africanas: de África occidental a España, el autor presenta un amplio panorama de investigación que inició con una ponencia titulada «Estudios africanos en las universidades de hoy», en el marco del VIII Congreso Internacional sobre el Discurso Artístico organizado por la Universidad de Oviedo en 2001. Desde entonces, ha explorado en múltiples publicaciones científicas la literatura del occidente africano desde la doble perspectiva didáctico-literaria. De ahí que su amplia experiencia investigadora le haya llevado a analizar el patrimonio oral de la literatura subsahariana en lengua española y crear así una bibliografía de referencia para los receptores de habla hispana. Por ello, el libro que aquí reseñamos se presenta como una monografía de marcado carácter divulgativo dirigida a un público hispanófono y que persigue el objetivo de visibilizar el mosaico literario de la oralidad en Africa occidental, a la par que proporciona su contextualización

\footnotetext{
${ }^{*}$ Acerca del libro de Vicente E. Montes Nogales, Literaturas orales africanas: de África occidental a España (Zaragoza, Libros Pórtico, 2020, 273 p. ISBN: 978-84-7956-207-6).
} 
en Europa al revelar la existencia de un espacio de creación literaria del oeste de África en España. Se trata, por consiguiente, de un libro que intenta acercar el objeto de análisis a un público amplio que comprende tanto a los especialistas como a todos aquellos lectores interesados en las especificidades de las literaturas orales del área geográfica estudiada. Asimismo, tal y como señala Ismael Diadé Haïdara en el prefacio que enmarca el inicio de la lectura, este monográfico no sólo resulta ser de gran interés para la población europea, sino que también lo es para la población africana «pues en él encontrarán un espejo de su profunda realidad» (p. 14).

En este contexto, Vicente Montes Nogales articula la monografía en torno a cuatro capítulos precedidos de un prefacio y de una introducción, y seguidos de una conclusión. En el primer capítulo el autor empieza reflexionando sobre la importancia acordada a la palabra en las sociedades africanas. En su análisis, el autor pone de manifiesto que, si bien los diferentes imperios tuvieron cierta influencia unificadora, el oeste de África es un área del continente que presenta categorías sociales complejas y diferencias socioculturales significativas. Para ello, hace un recorrido sobre los resultados de las investigaciones más relevantes en torno a los grupos sociales que componen el territorio subsahariano, deteniéndose en aquellos grupos en los que la palabra se convierte en el eje neurálgico, en torno al cual se articulan desde los ritos religiosos y los Consejos de ancianos hasta los actos cotidianos. De este modo, realza el investigador en este primer capítulo la admiración que sigue despertando el arte de contar en África occidental, sobre todo «cuando el discurso reúne valioso contenido y está bellamente expresado, pues es de provecho para el que lo escucha por su poder persuasivo y deleita por la elegancia con la que es expuesto» (p. 41).

Seguidamente, el autor se centra en la clasificación de los narradores tradicionales y el papel que desempeñan los ancianos en el proceso de transmisión del saber. En este segundo capítulo, resulta particularmente interesante observar la importancia que adquiere la edad en el arte de contar, ya que el conocimiento que aportan los años supone un activo sociocultural importante en materia de transmisión de saberes. De ahí que en el continente africano la muerte de un anciano suponga, tal y como verbaliza Hampâté Bâ, la pérdida «de un tesoro de conocimientos irremplazable» (p. 48). Luego se detiene especialmente en la evolución de la figura de los conocidos griots $^{1}$, desde que aparece la voz por primera vez en Relation $d u$

\footnotetext{
${ }^{1}$ Los griots son «los protagonistas de la oratoria [...] y a quienes se debe la divulgación de muchos conocimientos tradicionales» (p.59) en el África occidental. Se trata de una figura que puede clasificarse según sus funciones en: «los griots músicos, con frecuencia excelentes compositores y cantantes; los griots embajadores y cortesanos, ligados a una familia real o noble, y que se convierten en mediadores en caso de conflicto; y los griots genealogistas, historiadores y poetas, que se definen como grandes viajeros y narradores cuya vinculación a una familia no es obligatoria» (p. 78). En este sentido cabe señalar que también existen griots que pueden cumplir todas las funciones.
} 
voyage du Cap-Verd en 1637 hasta la actualidad. Se trata de un capítulo en el que el autor examina, además, una figura poco abordada por la literatura científica hasta el momento: las griottes. Con ello, Montes Nogales pone de relieve que las griottes también son figuras referentes y relevantes en el mosaico de las literaturas orales en África occidental. Tal vez el ejemplo más paradigmático que evoca en su libro sea el de Yandé Codou Sene, griotte oficial de Léopold Sédar Senghor. En este sentido, podemos afirmar que evocar la oralidad literaria en femenino significa dar voz y reconocer la labor de todas aquellas narradoras que han contribuido a la transmisión de las literaturas orales en el oeste africano. De igual modo, este análisis supone visibilizar esa otra mirada que influye en el arte de contar ya que, tal y como señala Christine Planté (2003: 658), «l'expérience humaine et la vision qu'on a du monde et de la culture n'est pas la même selon que les femmes y apparaissent seulement en position d'objets, d'inspiratrices ou de lectrices, ou si elles figurent aussi en position de productrices et créatrices».

En el tercer capítulo Vicente Montes Nogales expone con maestría cómo conviven «la fórmula laudatoria sencilla que identifica a un individuo; el panegírico que ensalza los méritos de un linaje; el cuento que reivindica desde un mundo ficticio los comportamientos correctos y condena los que no se adecúan a las normas» (p. 255), junto con el mito, la epopeya, el proverbio, la adivinanza y la canción. Estudiar las literaturas orales del África subsahariana conlleva, pues, acercarse a un mosaico de creación de marcado carácter testimonial, didáctico y referencial que no descuida el placer estético. En tal contexto, el autor señala la influencia que las tecnologías han tenido en la evolución de los géneros orales, ya que «la radio e internet ayudan a difundir en África los cuentos, aunque no cabe duda de que el proceso narrativo conoce modificaciones que lo alejan de la sesión tradicional» (p. 207).

Por otra parte, el éxodo rural y los procesos migratorios también conllevan una modificación del canon tradicional en el que se enmarcan literaturas orales oesteafricanas. De ahí que Montes Nogales haya enfocado la reflexión del cuarto capítulo de esta monografía hacia la influencia de los griots en España. Por ello, este último capítulo resulta, a nuestro parecer, no sólo original por la recopilación de testimonios que expone, sino también necesario ya que permite reflexionar en términos identitarios sobre los nuevos rostros de la movilidad y de la copresencia (Whitol de Wenden, 2013: 244). En efecto, manifestar la labor de Agnès Agboton y Boniface Ofogo Nkama como contadores profesionales en el territorio español supone reconocer esa otra realidad que compone un mosaico literario múltiple y plural, el cual pone a su vez de manifiesto la evolución de los cánones literarios tradicionales. De igual modo, resulta de especial interés observar la labor documental y testimonial realizada por el autor cuando expone la relación 
del griot Yeliba Souleymane y de su yatigui ${ }^{2}$ Amadou Taoré en el municipio toledano de Recas, así como la trayectoria vital del griot senegalés Ngor Mbaye afincado en localidad extremeña de Ribera del Fresno, o la experiencia de la griotte senegalesa Aïda Diagne que lleva casi treinta años dedicándose a la venta ambulante en mercados españoles. Se trata, por consiguiente, de un capítulo cuya reflexión abarca un ámbito artístico que podemos denominar xenografías literarias en el espacio de creación hispanohablante, ya que constatamos el surgimiento de un espacio literario transnacional que rompe con los cánones literarios tradicionales y presenta «une nouvelle réalité qui se forge au sein même d'une société désormais plurielle et qui s'inscrit dans un monde global» (Alfaro, Sawas \& Soto, 2020: 10).

A nuestro modo de ver, la lectura de este libro propone una reflexión singular que imbrica el punto de vista artístico-literario y la perspectiva intercultural, a la vez que ilustra una cartografía geopoética identitaria a través de las diferencias socioculturales. Se trata, por consiguiente, de una lectura que permite reflexionar en términos de diálogo, que promueve valores de tolerancia y respeto, que permite romper con los estereotipos y conocer mejor a esos nuevos integrantes de la sociedad cuyas trayectorias vitales no son homogéneas, aunque sí se encuentren íntimamente ligadas a los procesos migratorios. Así pues, consideramos que esta monografía representa una manera sugestiva y original de abordar las literaturas orales africanas tanto en el territorio subsahariano como en el propio territorio español; y esto se lleva a cabo desde una óptica doble que interesará al investigador y atraerá al lector no especializado.

\section{REFERENCIAS BIBLIOGRÁFICAS}

Alfaro, Margarita; Stéphane SAWAS \& Ana Belén SoTo [eds.] (2020): Xénographies féminines dans l'Europe d'aujourd'hui. Bruselas, Peter Lang.

PlANTÉ, Christine (2003): «La place des femmes dans l'histoire littéraire : annexe ou point de départ d'une relecture critique». Revue d'histoire littéraire de la France, 103: 3, 655-668.

WHITOL DE WENDEN, Catherine (2013): La question migratoire au XXIe siècle. Migrants, réfugiés et relations internationales. París, Presses de la Fondation Nationale des Sciences Politiques.

\footnotetext{
${ }^{2}$ El yatigui suele pertenecer a la casta o a la categoría social de los nobles y representa la figura del homenajeado, del protector o del patrón. Se trata de una persona a la que el griot dirige elogios y de la que el griot narra su genealogía. A cambio de tales servicios, el griot recibe dádivas o compensaciones económicas del yatigui, en función de las posibilidades de este.
} 